IJIET, e-ISSN 2548-8430, p-ISSN 2548-8422, Vol. 2, No. 2, July 2018

\title{
IJIET
}

International Journal of Indonesian Education and Teaching http://e-journal.usd.ac.id/index.php/IJIET

Sanata Dharma University, Yogyakarta, Indonesia

\section{SECONDARY SCHOOL STUDENTS' CONSTRUCTION OF KNOWLEDGE: THE CASE OF FRACTIONS DIVISION}

\author{
Veronika Fitri Rianasari and Hongki Julie \\ Mathematics Education Study Program, Sanata Dharma University \\ veronikafitri@usd.ac.id and hongki_julie@usd.ac.id \\ https://doi.org/10.24071/ijiet.v2i2.1172 \\ Received 23 April 2018; revised 20 June 2018; accepted 2 July 2018
}

\begin{abstract}
Fractions are well known to be difficult to learn, but it is should not be surprising considering the complexity of the concepts involved. In working with fractions, children learn new rules that often conflict with well-established ideas about whole numbers. Many studies have revealed that fractions division has been thought to be the most complex of the mathematical operations in elementary mathematics. However, fractions and the operations have been recognized as an important foundation for the understanding of our number system. Therefore, teachers should provide meaningful learning experiences that relate to division of fractions. This present study aimed to analyze secondary school students' construction of knowledge in fractions division. This descriptive study was conducted with 44 seventh grade students in Pangudi Luhur Junior High School in Yogyakarta, Indonesia. During a one-week unit of lesson on division of fractions, students were given a task-based activity specifically designed to promote students' understanding. Data sources in this study included observation of the learning process and a pre and posttest of students' conceptual knowledge and procedural computation skills. The result showed a significant improvement in students' conceptual knowledge and procedural knowledge.
\end{abstract}

Keywords: conceptual knowledge, division of fraction, procedural knowledge

\section{Introduction}

One of mathematics topics learned from elementary and continuing up to secondary school is fraction. Lortie-Forgues, Tian and Siegle (2015) argued that understanding of fractions plays an important role in learning the next mathematics concepts and fractions have many applications in everyday life. However, many research revealed some important issues about some challenges in teaching and learning fraction. The first issue is many students have great difficulty in understanding fraction (Ma, 1999 and Lortie-Forgues, Tian and Siegle, 2015). Furthermore, Fendel (1987 in Tirosh, 2000) and Ma (1999) revealed that division of fractions is considered to be the most difficult, the most mechanical and least understood topic in elementary mathematics. According to Ma (1999), the difficulty is not only the difficulties experienced by students in 
learning the fractions, but also the difficulties experienced by teachers in teaching the concept of fractions.

The second issue is about the way of teaching and learning mathematics, especially in Indonesia. Mathematics in Indonesian curriculum tended to be taught in a very formal way; teachers explain the mathematics operation and procedures, give some examples, and ask students to do the other similar problems (Armanto, 2002). In learning fractions, students are taught algorithms with little attempt to ground them in a meaningful experience.

Because of the complexity of division of fraction concepts, more time should be allocated in the curriculum for developing students' understanding of fractions division. But just more time is not sufficient to improve understanding; the emphasis of instruction should also shift from the development of algorithms for performing operations on fractions to the development of a quantitative understanding of fractions divisions. Considering this fact, the teaching and learning need to focus on how understanding fractions division can be taught. This need leads to the third issue namely explorative activities. In Realistic Mathematics Education (RME), it is important to give students the opportunity to explore some daily life contexts in which mathematics play a role.

\section{Theory}

\section{Realistic Mathematics Education (RME)}

The philosophy of RME is mathematics as a human activity, which means that mathematics must be connected to reality, stay close to students and shouldbe relevant to society (Gravemeijer, 1997). There are three main principles in the RME (Gravemeijer, 1997, Treffers, 1991, and Julie, 2014), namely:

\section{Guided reinvention through progressive mathematizing}

In realistic mathematics learning, students are given the opportunity to explore problems to experience a process similar to the process by which the mathematics was invented. Through solving a series of problem, students are expected to produce strategies evolved from informal to more formal procedures so that at the end a formal procedure can be found by students.

\section{Didactical phenomenology}

In RME, students explore phenomena or situation series that are meaningful for them. According to Freudenthal (1983, in Gravemeijer 1997), situations where a given mathematical topic is applied are to be investigated for two reasons. Firstly, to reveal the kind of application that have to be anticipated in instruction; secondly, to consider their suitability as points of impact for a process of progressive mathematization.

\section{Self-developed models}

In realistic mathematics learning, models are interpreted as mathematical representations of problems. Models are used, explored, and developed to bridge the difference in levels from concrete to formal levels. Therefore, the term model or symbol here is always associated with the process of mathematization. 


\section{Students' Knowledge of Division of Fractions}

When studying division, students can gain a lot of new knowledge, for example students can learn about rational and irrational numbers, place value, the connections among the four basic operations, as well as about the limits and power of relating mathematics to the real world (Ball, 1990). However, in many textbooks, introduction to fractions division states simply "Dividing by fraction is the same as multiplying by its reciprocal". There is little or no attention given to the meaning of divisions with fractions and division with whole numbers (Ball, 1990). Therefore, many students are puzzled that the answer to a problem such as $\frac{1}{3} \div \frac{1}{6}=2$ is bigger than the number they started with.

There are two common methods for division of fractions taught in elementary schools in many countries, namely common-denominator method and inversion method. Capps (1962) stated that textbooks in the past have favored the inversion method and the common-denominator method more often appears in meaningful teaching. Capps (1962) revealed that the inversion method of division of fractions reinforce students' skills in multiplication of fraction since the inversion method of fractions division requires multiplication as part of the computational procedures. In this research, the researchers facilitated students to give meaning to the inversion method so they really understand why in dividing by fraction is the same as multiplying by its reciprocal.

Tirosh (2000) explained that students' errors made in division of fractions can be categorized in three main categories:

\section{Algorithmically based errors}

These errors are made in the computational process when an algorithm is viewed as a meaningless series of steps. For example: ${ }^{3} \div{ }^{1}={ }^{4} \times{ }^{1}={ }^{4}={ }^{1}$ These

$$
\begin{array}{llllll}
\overline{4} & \overline{8} & \overline{3} & \overline{8} & \overline{24} & \overline{6}
\end{array}
$$

kinds of errors are usually explained as resulting from rote memorization of the algorithm.

\section{Intuitively based errors}

These errors result from misconceptions associated with division; students tend to overgeneralize properties of operations with natural numbers to fractions and to interpret division primarily using a primitive, partitive model of division.

\section{Errors based on formal knowledge}

These errors result from limited conceptions of the nature of fractions and inadequate knowledge related to properties of the operations. For example, students think that division is commutative and consequently argue that $\frac{1}{2} \div \frac{3}{4}=\frac{3}{4} \div \frac{1}{2}$

\section{Method}

This study was a descriptive study analyzing secondary school students' construction of knowledge in fractions division. The study was conducted with 44 seventh grade students in Pangudi Luhur Junior High School in Yogyakarta, Indonesia. 
During a one-week unit of lesson on division of fractions, students were given a task-based activity specifically designed to promote students' understanding. Data sources in this study included observation of learning process and a pre and posttest of students' conceptual knowledge and procedural computation skills.

\section{Findings and Discussion}

The research results were divided into three sections. Those are students' initial knowledge of fractions division, the learning process of division of fractions, and students' knowledge about fraction division in the post test.

\section{Students' initial knowledge of fractions division}

Students' initial knowledge of fraction division is revealed through a pre-test. In the pre-test, students were given a contextual problem that requires them to translate the contextual problem into a mathematical sentence and apply the knowledge of fractions to solve the problem. The problem given is as follows:

Mrs Surya has $2 \mathrm{~kg}$ of flour and $1 \frac{1}{4} \mathrm{~kg}$ of sugar.

She will make some cakes.

For each cake she makes, she needs $\frac{1}{2} \mathrm{~kg}$ of flour and $\frac{1}{4} \mathrm{~kg}$ of sugar.

How many cakes can be made by Mrs Surya?

Based on students' answer, it can be showed that there were only $16(36 \%)$ students who were able to translate the problem into a mathematical sentence and there were only 10 of them who can give correct procedure of fractions operations. The students' answer also revealed that there were some students who gave an incorrect mathematical sentence and the others directly gave the final answer.

The following are the students' strategy to solve the problem:

Students used repeated subtraction strategy

Flour (2 kg)

The first cake

$2-\frac{1}{2}=\frac{2}{1}-\frac{1}{2}=\frac{4-1}{2}=\frac{3}{2} \mathrm{~kg}$

The second cake

$\frac{3}{2}-\frac{1}{2}=\frac{3-1}{2}=\frac{2}{2}=1$

The third cake

$1-\frac{1}{2}=\frac{2-1}{2}=\frac{1}{2}$

The fourth cake

$\frac{1}{2}-\frac{1}{2}=0$

$$
\begin{aligned}
& \text { Sugar }\left(1 \frac{1}{4} \mathrm{~kg}\right) \\
& \text { The first cake } \\
& 1 \frac{1}{4}-\frac{1}{4}=\frac{5}{4}-\frac{1}{4}=\frac{5-1}{4}=1 \mathrm{~kg} \\
& \text { The second cake } \\
& 1-\frac{1}{4}=\frac{4-1}{4}=\frac{3}{4} \\
& \text { The third cake } \\
& \frac{3}{4}-\frac{1}{4}=\frac{3-1}{4}=\frac{2}{4} \\
& \text { The fourth cake } \\
& \frac{2}{4}-\frac{1}{4}=\frac{2-1}{4}=\frac{1}{4} \\
& \text { mak }
\end{aligned}
$$

Therefore, Mrs. Surya can make 4 cakes

Figure 1. Students' answer using repeated subtraction on the pre-test 
Figure 1 shows that the students were able to translate the problem into mathematics symbol and they used repeated subtraction strategy to find how manycakes that can be made by Mrs Surya.

\section{- $\quad$ Students used inversion method}

$$
\begin{aligned}
& \text { Flour } \\
& \begin{array}{l}
\text { Sugar } \\
2
\end{array}=2 \times \frac{1}{1}=\frac{4}{1}=4 \text { (cakes) } \\
& 2 \div \frac{1}{4}=\frac{5}{4} \times \frac{4}{1}=\frac{5}{1}=5 \text { (cakes) } \\
& \text { Therefore, Mrs. Surya can make } 4 \text { cakes } \\
& \text { Figure 2. Students' answer using } \\
& \text { inversion method and having correct } \\
& \text { conclusion on the pre-test }
\end{aligned}
$$

Students were able to translate the problem into mathematic symbols and they used the inversion method to find the answer.

- $\quad$ Students were not able to translate the problem into mathematics symbol

$$
\begin{aligned}
& \text { Cake ingredients owned: } 2+1 \frac{1}{4}=3 \frac{1}{4} \\
& \text { Cake ingredients needed: } \frac{1}{2}+\frac{1}{4}=\frac{2+1}{4}=\frac{3}{4}
\end{aligned}
$$

The number of cakes that can be made:

$$
3 \frac{1}{4} \div \frac{3}{4}=\frac{13}{4} \div \frac{3}{4}=\frac{13}{4} \times \frac{4}{3}=\frac{13}{3}=4 \frac{1}{3}
$$

Therefore, Mrs. Surya can make 4 cakes.

Figure 4. Students' answer is having incorrect interpretation of the problem but having the correct inversion procedure on the pre-test.

The pre-test result showed that many students that can apply inversion method appropriately while dividing fractions, but some students who apply this method made mistakes in drawing conclusions. In addition, pre-test results showed that some students used informal strategy to solve the problems i.e. repeated subtraction strategy. The repeated subtraction strategy seems to be more meaningful for the students, as no student has made a mistake in drawing conclusions with this strategy.

\section{The learning process of division of fractions}

In facilitating students to understand the fractions division operation, the researchers designed some contextual problems in which the students can 
construct the meaning of the fraction division operation through the problem solving process. As has been revealed in the pre-test, most of the students have mastered the inversion method when dividing fractions but they have difficulty in understanding the concept of fractions division and inversion method so that they have difficulty in applying that knowledge to solve contextual problems. The following is one of the contextual problems used in learning of fractions division.

Mother has a 1,5 litres drinking bottle. The bottle only contains three-quarters of the portion. Mom will pour the water into some 250 $\mathrm{ml}$ small bottles.

a. How many small bottles can be filled with the water from a large bottle?

b. How many part of the water in the bottle which is not fully charged?

The mathematical concept in the contextual problem is the concept of division operation. In solving the problem, students can use their knowledge of the division of integers, if they first convert the unit of volume to obtain integers.If students do not convert the unit of volume, they will work with decimals or fractions.

The following is the answer given by most of the students in the class:

1,5 litre $=1500 \mathrm{ml}$ (conversion of unit's volume).

$1500 \mathrm{ml} \div 4=375 \mathrm{ml}$

$375 \mathrm{ml} \mathrm{x} 3=1125 \mathrm{ml}$.

$1125 \mathrm{ml} \div 250 \mathrm{ml}=4$ bottles and the rest is $125 \mathrm{ml}$

From the students' answer, the teacher asked the students to make an illustration of the answer. Here is the illustration given by the students:
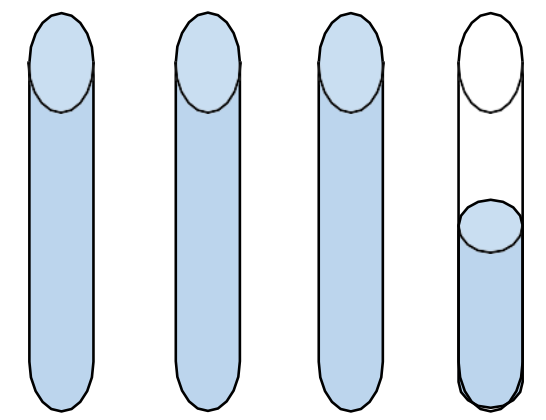

$250 \mathrm{ml}$

$250 \mathrm{ml} 250 \mathrm{ml}$

$125 \mathrm{ml}$

From the illustration, the teacher led a discussion and so that the student can derive the conclusion that $125 \mathrm{ml}$ is a half of $250 \mathrm{ml}$. From the discussion, the students can conclude that there are 4 bottles of $250 \mathrm{ml}$ that can be fully filled with water and there is 1 bottle of $250 \mathrm{ml}$ that is only filled one half. Furthermore, the teacher asked the students not to convert the unit so that the students must perform the division operation involving decimals or fractions i.e. $1,125 \div 0,25$ or $1_{\overline{8}} \frac{1}{4} \div \frac{1}{4}$. With this kind of activities, the students are guided to give 
meaning of the following operations $1_{\frac{8}{8}}^{1} \div \frac{1}{4}=4 \frac{1}{2}$, and to make sense why when they divide by a number less than one, the quotient is larger than the dividend.

In the process of learning, teachers play a role in giving opportunities to students to express ideas, stimulate social interaction, build mathematical concepts contained in the contextual problems, and clarify opinions or answers given by students.

\section{Students' knowledge about fractions division on the post test}

After one-week unit of lesson, the students were given a post-test. The posttest contains a bare numbers problem that requires them to carry out a fractional division procedure and a contextual problem that requires them to translate the contextual problem into a mathematical sentence and apply the knowledge of fractions division to solve the problem. The problem given is as follows:

1) $\frac{5}{8} \div \frac{1}{4}=\ldots$

2) Yesterday Mrs. Ana bought $\frac{23}{4} \mathrm{~kg}$ of rice.

Today, Bu Ana buys another $2 \frac{1}{2} \mathrm{~kg}$ of rice.

a) How many kilograms of rice does Mrs Ana have?

b) If $\mathrm{Bu}$ Ana wants to share the rice to some of her neighbours who each need $\frac{3}{4} \mathrm{~kg}$ of rice, how many neighbours get the rice?

Based on the students' answer in solving bare numbers problem, there were 37 students $(84 \%)$ who were able to use inversion method in dividing fractions but 4 of them were not able to derive the correct final answer because they made mistakes in multiplying and simplifying fractions.

The following are the students' strategies used to solve the bare numbers problem:

- Students used inversion method and got the correct final answer

There were 33 students who were able to use inversion method correctly infractions division.

$$
\frac{5}{8} \div \frac{1}{4}=\frac{5}{8} \times \frac{4}{1}=\frac{20}{8}=2 \frac{1}{2}
$$

Figure 5. Students' answer using inversion method correctly on the post-test Students used inversion method but made errors in calculations

$$
\frac{5}{8} \div \frac{1}{4}=\frac{5}{8} \times \frac{4}{1}=\frac{32}{8} \times \frac{5}{8}=\frac{310}{8}=\frac{31}{80}
$$

Figure 6. Students' errors on the post-test in multiplying and simplifying fractions

Students' answer on the post-test shown in figure $6,7,8$ reveal that many students made algorithmically based errors in addition to errors in technical calculations e.g. errors in the division of integers. Their answers show that the 
algorithm in dividing or multiplying fractions is viewed as a meaningless series of steps.

$$
\frac{5}{8} \div \frac{1}{4}=\frac{5}{18} \times \frac{4^{2}}{1}=\frac{10}{1}
$$

Figure 7. Students' errors on the post-test in simplifying fractions multiplication

Furthermore, based on the students' answer in solving the contextual problem, 39 students $(89 \%)$ were able to translate the problem into mathematical sentence, only 30 out of them are able to derive the correct final answer. In this paper, the researchers only focus on question $2 b$, because this paper focus on students' comprehension in fractions division.

$$
\frac{5}{8} \div \frac{1}{4}=\frac{5}{8} \times \frac{4}{1}=\frac{32}{5}
$$

Figure 8. Students' errors on the post-test in multiplying fractions

The following are the students' strategies in solving a contextual problem:

Students used inversion method correctly and derive the correct final answer Figure 9. Students' answer using inversion method correctly and having the correct final

The amount of rice owned by Mrs. Ana:

$$
2 \frac{3}{4}+2 \frac{1}{2}=4 \frac{3+2}{4}=4 \frac{5}{4}=4+1 \frac{1}{4}=5 \frac{1}{4}
$$

The number of neighbors who get the rice:

$$
5 \frac{1}{4} \div \frac{3}{4}=\frac{21}{4} \div \frac{3}{4}=\frac{21}{4^{1}} \times \frac{4^{1}}{3}=\frac{21}{3}=7
$$

Therefore, there are 7 neighbors who get the rice

answer on the post-test

There were only 26 students (59\%) who were able to use inversion method correctly and do the calculation correctly.

- Students used inversion method but made errors in calculation

The amount of rice owned by Mrs. Ana:

The number of neighbors who get the rice:

$$
2 \frac{3}{4}+2 \frac{1}{2}=4 \frac{4}{6}
$$

$$
4 \frac{4}{6} \div \frac{3}{4}=4 \frac{6}{4} \times \frac{4}{3}=4 \frac{16}{18}
$$

Figure 10. Students' errors on the post-test in adding fractions, in using inversion method, and in multiplying fractions

Figure 10 shows that these students made errors because they did not understand the concepts in fractions and its operations, for example in adding, multiplying, and dividing fractions. Therefore these errors can be categorized as 
algorithmically based errors; these errors resulted from rote memorization of the algorithm.

- Students used repeated addition

The amount of rice owned by Mrs. Ana:

$$
2 \frac{3}{4}+2 \frac{1}{2}=\frac{11}{4}+\frac{5}{2}=\frac{11+10}{4}=\frac{21}{4}=5 \frac{1}{4}
$$

The number of neighbors who get the rice:

1 neighbor: $\frac{3}{4} \mathrm{~kg} ; 2$ neighbors: $\frac{6}{4} \mathrm{~kg} ; 3$ neighbors: $\frac{9}{4} \mathrm{~kg} ; 4$ neighbor: $\frac{12}{4} \mathrm{~kg}$;

5 neighbor: $\frac{15}{4} \mathrm{~kg}$; 6 neighbors: $\frac{18}{4} \mathrm{~kg} ; 7$ neighbors: $\frac{21}{4} \mathrm{~kg}$

Therefore, there are 7 neighbors who get the rice

Figure 11. Students' answer using repeated addition and having the correct final answer on the post-test

There are 2 students used repeated addition shown in Figure 11. This strategy seems to be more meaningful for them because they were able to get the conclusions correctly. However, this strategy is inefficiently used if the problem involves a relatively large number. This strategy also implies that the student's understanding might not have reached the formal level of understanding of the fractions division operation.

\section{Conclusion}

The students in this research were provided with the opportunities to develop an understanding of the concepts of fractions divisions in order to make sense algorithms of fractions division that they have learned in elementary school. The impact of this learning process can be seen from the results of the pre-test and posttest. The result of the pre-test showed that most of the students were not able to apply their knowledge of fractions in solving contextual problems, and alsothey made algorithmically based errors; errors resulted from rote memorization of procedures. The post-test showed a positive progress on students' understanding and skills in solving problems both problems that require procedural understanding as well as conceptual understanding although there are still some students who did not show a deep understanding of the concept of fractions division. This positive progress can be achieved due to the use of appropriate contextual problems in learning process that enable the students to solve the problems by linking the problem with their prior knowledge, and also because of the teacher's role that facilitates the discussion so that the students actively engagein making sense of procedures and the result of calculation using the procedures.

\section{References}

Bulgar, S. (2003). Children's sense-making of division of fractions. The Journal of Mathematical Behavior, 22(3), 319-334.

Capps, L. R. (1962). Division of fractions: A study of the common-denominator 
method and the effect on skill in multiplication of fractions. The Arithmetics Teacher, 9(1), 10-16.

Gravemeijer, K. (1997). Instructional design for reform in mathematics education. The role of contexts and models in the development of mathematical strategies and procedures. Utrecht: CD- $\beta$ Press, 13-34.

Isik, C., \& Kar, T. (2012). An error analysis in division problems in fractions posed by pre-service elementary mathematics teachers. Educational Sciences:Theory and Practice, 12(3), 2303-2309.

Julie, H., Suwarsono, S., \& Juniati, D. (2014). Understanding profile from the philosophy, principles, and characteristics of rme. Journal on Mathematics Education, 5(2), 148-159.

Kribs-Zaleta, C. (2006, November). Invented strategies for division of fractions. Proceedings of the 28th Annual Meeting of the North American Chapter of the International Group for the Psychology of Mathematics Education: Vol. 2,(pp. 371-376).

Ma, L. (1999). Knowing and teaching elementary mathematics. Mahwah, NJ: Lawrence Erlbaum Associates.

Newstead, K., \& Murray, H. (1998). Young students' constructions of fractions. PME, 22(3), 295-302.

Tirosh, D. (2000). Enhancing prospective teachers' knowledge of children's conceptions: the case of division of fractions. Journal for Research in Mathematics Education, 31(1), 5-25.

Treffers, A. (1991). Didactical background of a mathematics program for primary education. In L. Steefland (Ed.), Realistic mathematics education in primary school, (pp. 21-56). Utrecht: CD- $\beta$ Press. 